\title{
Visualization and Quantification of Solute Diffusivity in Cracked Concrete by X-Ray CT
}

\author{
M. Henry and T. Sugiyama \\ Environmental Material Engineering Laboratory, Faculty of Engineering, Hokkaido University \\ I. S. Darma \\ Environmental Material Engineering Laboratory, Graduate School of Engineering, Hokkaido University
}

\begin{abstract}
This paper explores the usage of microfocus X-ray computed tomography (CT) for visualization and quantification of diffusion phenomena in cracked concrete. Mortar specimens of varying shapes (prismatic and cylindrical), crack types (artificial and splitting tensile), and binder compositions (OPC and fly ash) were prepared. Cesium carbonate $\left(\mathrm{Cs}_{2} \mathrm{CO}_{3}\right)$ was used as a tracer in the diffusion test because it has high X-ray absorption due to its high atomic number and thus contrasts with mortar and air voids in the CT images. Image processing and analysis was carried out to visualize and quantify the diffusion behavior in 3D space. In addition, the profile of the solute concentration in cracked mortar was determined based on the measured CT numbers. Fick's second law could then be used to determine the diffusion coefficient of the solute. It was found that the diffusion coefficients along the crack were on the scale of $10^{-8}$ to $10^{-11} \mathrm{~m}^{2} / \mathrm{s}$, which implies that the transport mechanism along the crack was not solely by diffusion but controlled by the degree of saturation as well as the crack opening width. Diffusivity in the uncracked matrix, however, was reduced to the scale of $10^{-12} \mathrm{~m}^{2} / \mathrm{s}$. Fly ash mortar exhibited a lower diffusion coefficient in the uncracked matrix compared with the OPC mortar with an equivalent crack opening width.
\end{abstract}

\section{INTRODUCTION}

A concrete structure will typically undergo cracking during its service life, which may be caused by a variety of factors including construction (improper curing), chemical (early-age shrinkage), mechanical (loading fatigue), and environmental (temperature and moisture content) factors. Crack formation due to these factors may lead to a reduction in long-term structural durability due to the increased potential for deleterious materials, such as water, chloride ions, or carbon dioxide penetrating the concrete surface and accelerating the deterioration process. It is therefore important to clarify the relationship between cracking and structural durability by examining the effect of cracks on material transport.

The transport phenomenon of a solution in cracked space is, however, not yet fully understood. Solute transport generally occurs by two means-capillary absorption or diffusion-or a combination of the two. Absorption is believed to take place when the crack is dry, whereas diffusion can only occur when the crack space is saturated with water; transport by absorption is faster than that by diffusion. The degree of saturation inside the crack space thus plays an important role in the transport of a solution in cracked concrete, along with the crack geometry. Unfortunately, both degree of saturation and actual crack geometry are difficult to evaluate, and previous research has used fitted data rather than direct observation of the crack space (Jang, Kim, \& Oh, 2011).

X-ray computed tomography (CT) provides a nondestructive means of examining the internal structure of an object in three dimensions and, when combined with image analysis techniques, can enable the quantitative evaluation of an object's internal structure through the comparative analysis of the X-ray absorption of materials with different densities within the object. In the concrete field, X-ray CT has been applied to a variety of research areas, including pore structure characterization, freeze-thaw and fire damage, and diffusivity in cracks (Darma, Sugiyama, \& Promentilla, 2013; Henry, Darma, \& Sugiyama, 2014; Promentilla \& Sugiyama, 2010; Sugiyama, Promentilla, Hitomi, \& Takeda, 2010). This technology is uniquely suited to analyzing crack characteristics in particular, as air voids inside concrete-both connected (cracks) and isolated-have little to no X-ray absorption properties, and thus, contrast highly with the cement paste and aggregates. Conversely, materials with very high X-ray absorption properties can be used as a tracer to examine diffusion behavior in concrete, and cesium carbonate solution has been found to be useful for this purpose due to its high contrast with a 
cement mortar matrix (Kikkawa, Sugiyama, Darma, \& Shimura, 2012).

In this paper, the results of two studies on solute diffusivity that used a cesium carbonate solution as a tracer to simulate liquid ingress in cracked concrete are introduced and summarized (Darma et al., 2013; Ikeda, Sugiyama, Kikkawa, \& Shimura, 2012;). These studies examined the solute diffusion under a variety of conditions using X-ray CT to both visualize and quantify the diffusion behavior, and the results provide valuable information for better understanding the transport phenomenon of a solution in cracked concrete.

\section{EXPERIMENTAL PROGRAM}

The experimental program was carried out in several stages involving specimens with different shapes, saturation conditions, crack types, and binder compositions. An overview is shown in Table 1.

Table 1. Overview of test conditions.

\begin{tabular}{ccccc}
\hline Code & $\begin{array}{c}\text { Specimen } \\
\text { shape }\end{array}$ & $\begin{array}{c}\text { Saturation } \\
\text { condition }\end{array}$ & $\begin{array}{c}\text { Crack } \\
\text { type }\end{array}$ & Binder \\
\hline P1 & Prism & Dry & Artificial & OPC \\
P2 & Prism & Saturated & Artificial & OPC \\
C1 & Cylinder & Saturated & S.T. & OPC \\
C2 & Cylinder & Saturated & S.T. & FA \\
\hline
\end{tabular}

Note: S.T. = splitting tensile.

\subsection{Materials}

Mortar was prepared using ordinary Portland cement (OPC, $\rho=3.16 \mathrm{~g} / \mathrm{cm}^{3}$ ), Japan Industrial Standard (JIS) type-II fly ash (FA, $\rho=2.16 \mathrm{~g} / \mathrm{cm}^{3}$ ), crushed sand (S, $\rho=2.67 \mathrm{~g} / \mathrm{cm}^{3}$ for P1 $\rho=2.71 \mathrm{~g} / \mathrm{cm}^{3}$ for $\mathrm{C} 1-\mathrm{C} 2$ ), and ordinary tap water $(\mathrm{W})$. For $\mathrm{P} 2$, limestone was used for fine aggregate. An air-entraining agent was also included to control air content.

Mix proportions for each of the test series are given in Table 2. For P1-P2, the water-binder ratio (W/B, where binder includes both OPC and FA) was set to 0.5 ; for $\mathrm{C} 1-\mathrm{C} 2$, it was set to 0.6 , and the fly ash replacement ratio (FA/B) was 0.3 . It should also be noted that, for series $\mathrm{P} 1$, the maximum fine aggregate size was $5 \mathrm{~mm}$, whereas for the other series, it was reduced to $1.7 \mathrm{~mm}$ for a finer matrix.

Table 2. Mix proportions and properties.

\begin{tabular}{cccccc}
\hline Code & W/B & FA/B & S/B & $\begin{array}{c}\text { Max. agg. } \\
\text { size }(\mathbf{m m})\end{array}$ & $\begin{array}{c}\text { Comp. strength } \\
(\mathrm{MPa})\end{array}$ \\
\hline P1 & 0.5 & - & 1.5 & 5.0 & $49.2(28$ days $)$ \\
P2 & 0.5 & - & 2.5 & 1.7 & $45.7(28$ days $)$ \\
C1 & 0.6 & - & 2.0 & 1.7 & $21.2(91$ days $)$ \\
C2 & 0.6 & 0.3 & 2.0 & 1.7 & $28.7(91$ days $)$ \\
\hline
\end{tabular}

\subsection{Specimens}

Specimens were prepared in two shapes as shown in Figure 1. For the prismatic specimens, mortar beams $(40 \mathrm{~mm} \times 40 \mathrm{~mm} \times 160 \mathrm{~mm})$ were first cast and cured for 470 (P1) or 320 days (P2) in water. At the end of the curing period, the beams were cut to a size of $20 \mathrm{~mm} \times 20 \mathrm{~mm} \times 40 \mathrm{~mm}$, and an artificial crack was introduced by cutting. The artificial crack was centered in the bottom of the specimen and had a width of $2 \mathrm{~mm}$ and depth of $20 \mathrm{~mm}$. In the case of the dry specimen (P1), drying was then carried out by placing the specimen in an oven at $105\left({ }^{\circ} \mathrm{C}\right.$ for 24 hours. Before the diffusion test, adhesive tape was applied to the four vertical sides of the specimens to prevent solute diffusion.
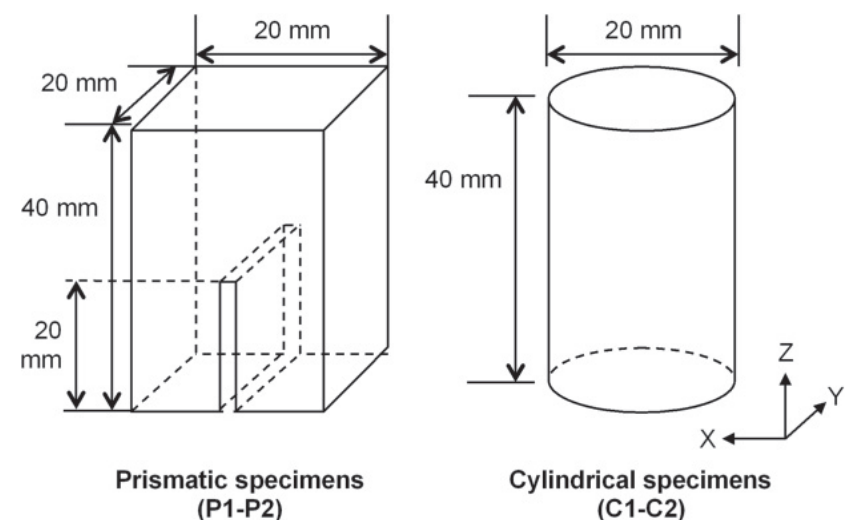

Figure 1. Specimen dimensions.

Cylindrical specimens were $\Phi 20 \mathrm{~mm} \times 40 \mathrm{~mm}$ in size and were removed by coring from $40 \mathrm{~mm} \times 40 \mathrm{~mm} \times 160 \mathrm{~mm}$ beams after 91 days of water curing. The specimens were wrapped with a heat-shrinkable tube to prevent failure of the specimen under loading and to limit solute diffusion to only the axial direction. Controlled splitting tests were carried out to induce a crack along the length of each cylindrical specimen, with final crack opening displacements (after unloading) of $152 \mu \mathrm{m}$ (C1) and $127 \mu \mathrm{m}$ (C2). After cracking, specimens were then immersed in water for an additional $24 \mathrm{~h}$ to increase saturation.

\subsection{Tracer solution}

In this study, a cesium carbonate $\left(\mathrm{Cs}_{2} \mathrm{CO}_{3}\right)$ solution was used as a tracer to visualize the solute diffusivity in the crack space and in the mortar matrix. Cesium carbonate can serve as an excellent tracer in concrete because it has a high X-ray absorption in contrast to concrete and its constituent materials. X-ray absorption (represented by the CT number in the case of the microfocus CT system used in this study) has a linear relationship with the tracer concentration (Darma et al., 2013). The solution was prepared by 
mixing cesium carbonate powder $\left(\rho=4.07 \mathrm{~g} / \mathrm{cm}^{3}\right)$ with water at a concentration of $40 \%$ by weight $(1.84$ $\mathrm{mol} / \mathrm{L}$ ), based on previous experimental results, which showed good contrast during image analyses at that concentration level (Ikeda et al., 2012).

\subsection{Diffusion test}

The conditions of the diffusion test for both sets of specimens are outlined in Figure 2. Both the top and bottom surfaces of the specimens were exposed, and the immersion depth was $2 \mathrm{~mm}$. For the prismatic specimens, immersion was carried out outside the X-ray CT machine, and specimens were removed from the solution during scanning, which took place 3 , 12 , and $24 \mathrm{~h}$ after the start of the diffusion test. For the cylindrical specimens, the diffusion test was carried out in situ; that is, the test was carried out inside the X-ray CT scanner, and the specimen was not moved in between scans. Scanning of cylindrical specimens took place before the start of the test and after 1, 3, 9, and $24 \mathrm{~h}$.

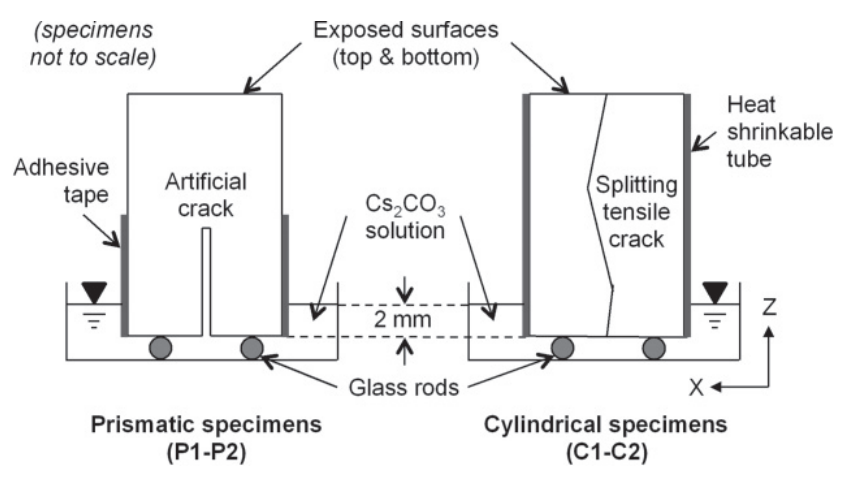

Figure 2. Diagram of diffusion test conditions.

\subsection{X-ray CT image acquisition}

$\mathrm{X}$-ray $\mathrm{CT}$ is a powerful technique for investigating the 3D microstructure of a material. As summarized by Promentilla and Sugiyama (2010) and Landis and Keane (2010), the concept of X-ray CT is similar to that of computer axial tomography (CAT or CT) scans in the medical field, in which a $3 D$ digital image is reconstructed from a series of $2 \mathrm{D}$ images or "slices." Each voxel (3D pixel) within the 3D digital image has an associated X-ray absorption value that can be correlated to material density, and thus, the internal structure can be determined based on the arrangement of the voxels in a 3D space.

Slice images are generally constructed on a gray scale from 0 (black) to 255 (white). The gray scale value (GSV) is calculated from the CT value, which in turn, is based on the X-ray absorption coefficient of a material. The GSV can thus be considered a representation of material density, where lighter shades represent higher density and darker shades lower density. Since the cesium carbonate solution has a much higher density than the concrete matrix, it will show up as a lighter shade in the images, with very high concentrations showing up as white.

In this study, a desktop microfocus CT system was used for acquiring the $3 \mathrm{D}$ images of the cracked specimens. The setup consists of a microfocus X-ray emitter, a rotation table, an image intensifier detector with CCD camera, and an image processing unit, as illustrated in Figure 3. The acquired slice images were $1024 \times 1024$ pixels in size, with a pixel size of $37 \mu \mathrm{m} \times 37 \mu \mathrm{m}$ and slice thickness of $80 \mu \mathrm{m}$ for P1-P2 and a pixel size of $22 \mu \mathrm{m} \times 22 \mu \mathrm{m}$ and slice thickness of $44 \mu \mathrm{m}$ for $\mathrm{C} 1-\mathrm{C} 2$.

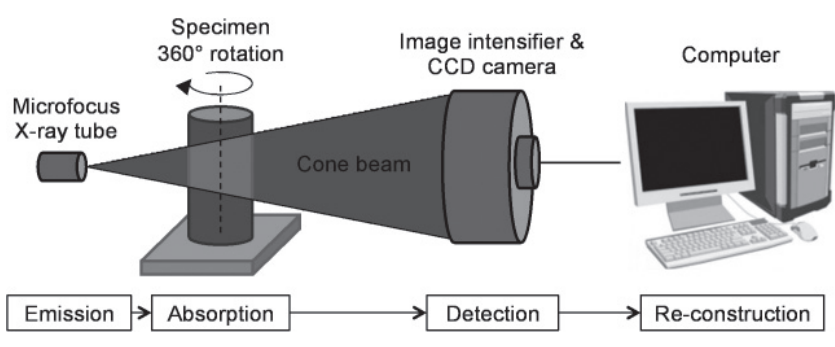

Figure 3. Setup for X-ray CT image acquisition.

\section{RESULTS AND DISCUSSION}

\subsection{Images of diffusion in prismatic specimens}

Cross-section images ( $X-Z$ plane) of the prismatic specimens during the diffusion test are shown in Figure 4. It should be noted that, for P1 at 3 and $12 \mathrm{~h}$, the images appear darker due to different contrast settings during image reconstruction.

In the case of the dry specimen (P1), it can be seen that the cesium solution moved upwards from the exposed surface, with greater progression in the areas around the artificial crack. The difference in depth between areas closer to and further away from the crack is more pronounced at $3 \mathrm{~h}$ but decreased by $24 \mathrm{~h}$. In addition, the line indicating the depth to which the solution progressed was distinct and the saturated area appeared to be of a relatively similar GSV value, which suggests that the variation in the solution concentration in the saturated areas was low and that it was moving as a front through the cement paste.

In contrast to the dry specimen, diffusion of the cesium solution in the saturated specimen (P2) occurred almost entirely along the surface of the artificial crack. After $3 \mathrm{~h}$ of exposure, the solution had already reached the tip of the artificial crack and some diffusion into the mortar matrix had occurred. From 3 to $24 \mathrm{~h}$, diffusion of the solution continued into the mortar matrix, mainly in the horizontal direction but with some progression in the vertical direction from the artificial crack tip as well. 

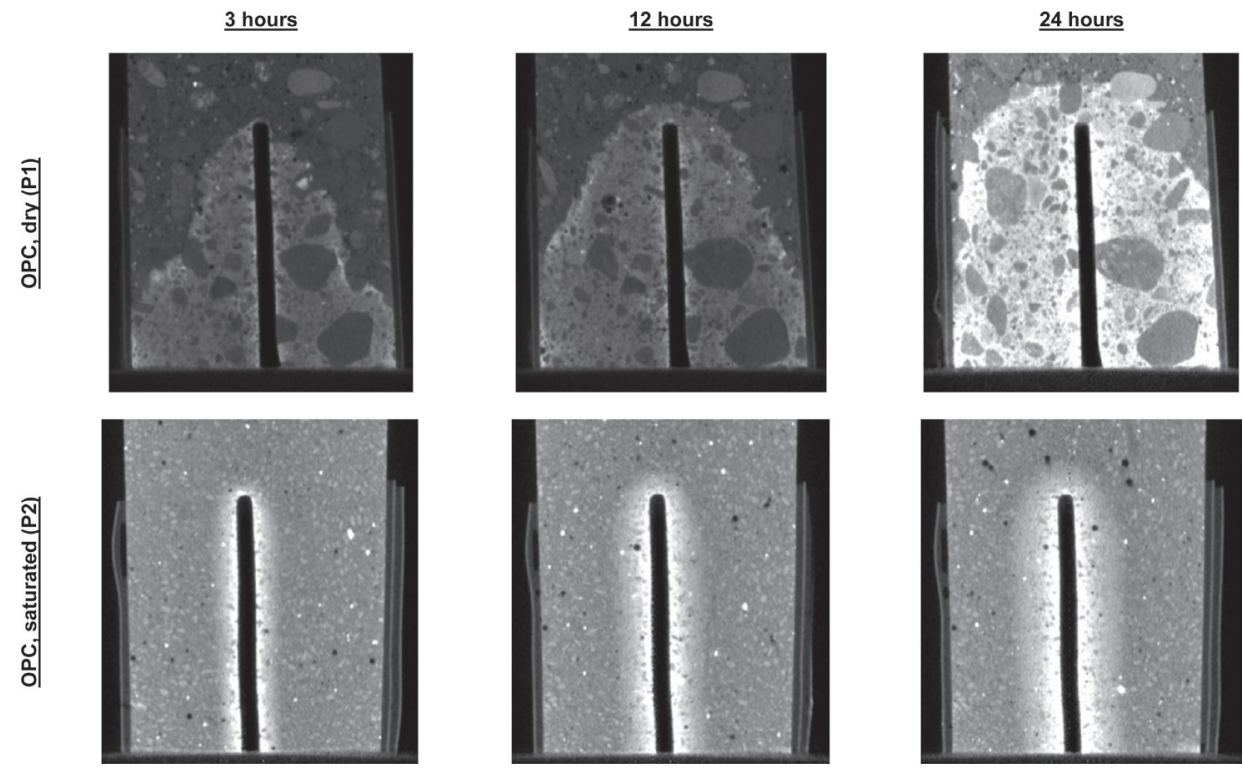

Figure 4. $X-Z$ cross-section images of solute diffusion in prismatic specimens over time ( $y=18.9 \mathrm{~mm}$, approx. center of the specimen).

Unlike the dry specimen, the solution did not progress as a distinct, clear front, but with a decreasing concentration from the crack surface; this can be seen in the gradation from the gray of the mortar matrix to the brighter white in the crack surface area where the concentration of the solution was high. For both prismatic specimens, no solution was present in the crack itself during the CT scan, which may be due to the removal of the specimen from the test solution in between scans or the large width of the artificial crack.

\subsection{Estimating penetration depth from CT value}

The penetration depth and change in the cesium solution concentration from the crack surface can be estimated by analyzing the change in the $\mathrm{CT}$ value along a line segment. This method is summarized in Figure 5 using the case of the saturated P2 specimen at $24 \mathrm{~h}$ as an example. From the CT value profile, the decrease in solution concentration from the crack surface can be clearly observed, and the penetration depth can be estimated as roughly $3.5 \mathrm{~mm}$. This approach can be used to calculate the diffusion coefficient when the line profiles being compared are from the exact same location at different time points; however, in the case of the prismatic specimens, the specimens were removed from the X-ray CT machine in between scans, so the CT profile along the line segments cannot be from the exact same location. In order to calculate the diffusion coefficient of the solution using X-ray $\mathrm{CT}$, the in situ test is necessary.

\subsection{Images of diffusion in cylindrical specimens}

Cross-section images ( $X-Z$ plane) of the cylindrical specimens during the diffusion test at a height of $9 \mathrm{~mm}$ are shown in Figure 6. As this test was conducted in situ, the specimen did not change position between images, so specific points in the specimens can be compared directly over time.

At the selected height, which is just below the center of the specimen in the vertical direction, the increase in cesium solution over time could be clearly seen in both the OPC and fly ash specimens. After $1 \mathrm{~h}$, the solution was mostly concentrated in the center of the
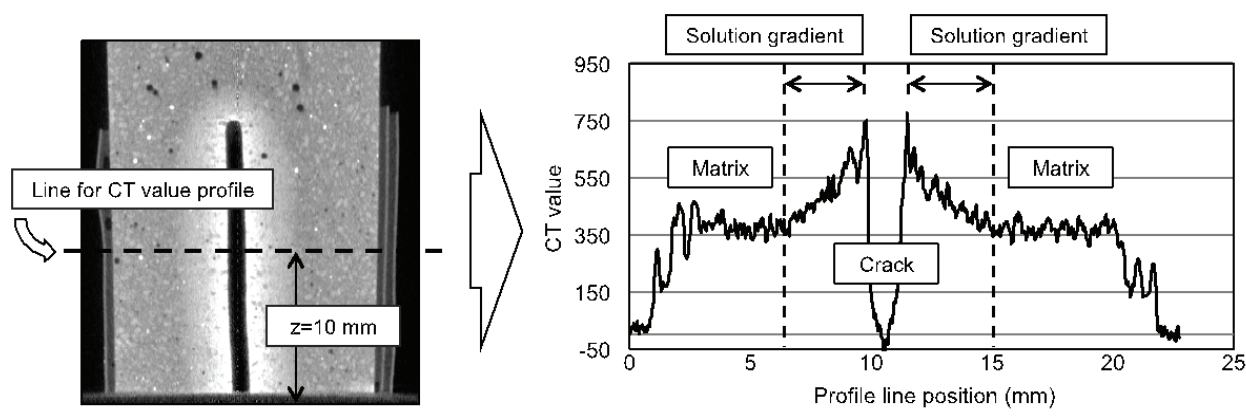

Figure 5. Method for calculating penetration depth of cesium solution from CT value profile (saturated specimen P2 at $24 \mathrm{~h}$ ). 

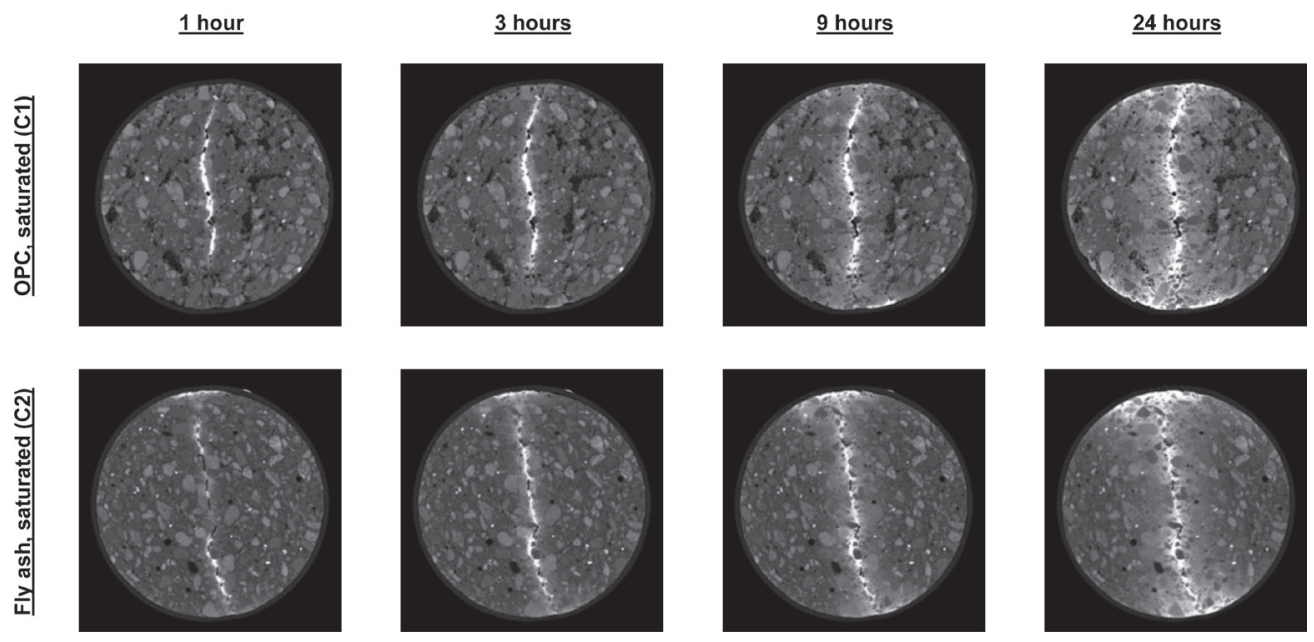

Figure 6. $X-Y$ cross-section images of solute diffusion in cylindrical specimens over time ( $z=9 \mathrm{~mm}$, just below the center of the specimen).

crack for the OPC specimen and present in some areas of the crack in the fly ash specimen, but from 3 to $9 \mathrm{~h}$ it diffused throughout both crack spaces. By $24 \mathrm{~h}$, the solution mostly filled both cracks and also began to diffuse into the mortar matrices from the crack walls. Solute diffusion could also be observed in the space between the specimens and the heatshrinkable tubes. Even by $24 \mathrm{~h}$, however, some air voids could still be identified in the crack space itself; these show up as black dots surrounded by the white cesium solution. This indicates that the cracks were not fully saturated at the start of the test, despite being immersed in water for $24 \mathrm{~h}$ prior to the test.

To visualize the diffusion of the cesium solution in three dimensions, image analysis software was used to isolate the change in CT value due to the solution by subtracting the initial condition images from the images at each time point. Since the specimen did not move during the diffusion test and the only change in X-ray absorption was due to solute diffusion, the difference between the initial condition and the condition at a given time point could be attributed to
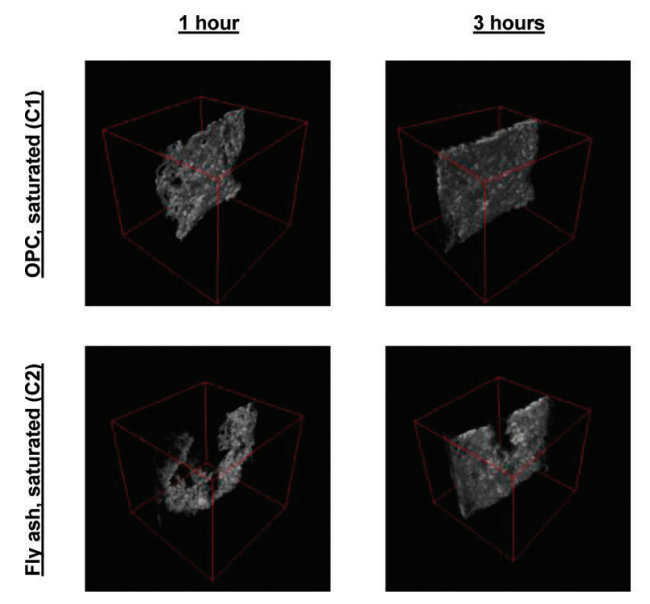

the change in solution concentration. The results of the image analysis and reconstruction are shown in Figure 7. For both the OPC and fly ash specimens, the cesium solution could be seen to first move deeply into the cracks before gradually expanding in the lateral direction through the crack walls. However, the solution appeared to fill the crack in the OPC specimen faster than the crack in the fly ash specimen, which may be attributed to the greater saturation degree of the crack in the OPC specimen. The crack opening displacement of the fly ash specimen was slightly smaller than that of the OPC specimen, which may have restricted, to some extent, the depth to which water could penetrate during the $24 \mathrm{~h}$ of water immersion before the diffusion test began.

\subsection{Diffusion coefficient in crack}

To quantify the observed solute diffusion behavior, the diffusion coefficient within the crack was calculated. After obtaining the CT profile along a line segment perpendicular to the crack (following the method previously introduced in Figure 5), the profile of the

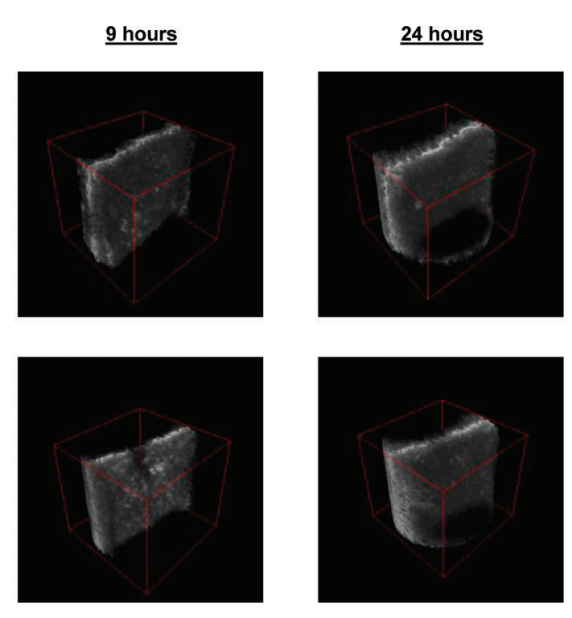

Figure 7. Three-dimensional reconstruction of solute diffusion in cylindrical specimens over time. 
cesium solution alone could be obtained by subtracting the profile of the initial condition along the same line segment. This process was repeated for the entire slice stack at selected heights, and at 10 regions of interest per image where the crack was filled with the solution. The average of the maximum observed CT number after isolating the cesium solution profile was then converted into the cesium solution concentration using the calibration data provided by previous research (Darma et al., 2013). Finally, the diffusion coefficients were calculated using a solution of Fick's second law under the proper boundary conditions.

The calculation results are shown in Table 3. During the first hour, the diffusion coefficient of the cesium solution in the crack is greater than the diffusion coefficient of cesium in free water $\left(2.06 \times 10^{-9} \mathrm{~m}^{2} / \mathrm{s}\right.$, Li \& Gregory, 1974; Flury \& Gimmi, 2002). This implies that, during the first hour, the movement of the cesium solution in the crack may have involved a transport mechanism other than molecular diffusion. During the remaining test period, however, the diffusion coefficient decreased to a value lower than that of diffusion in free water, which suggests that the movement of the solution was controlled by diffusion during that time period.

When comparing the diffusion coefficient in the crack between the OPC and fly ash specimens, it can be seen that the results are fairly similar. It was previously introduced that the crack opening displacement for the fly ash specimen was smaller than, although similar, to that of the OPC specimen. The constrictivity of the crack-a measurement of the variation in crosssectional width of a crack along its length-in the fly ash specimen was higher than of the crack in the OPC specimen (Darma et al., 2013). That is, there was more variation in the crack width in the fly ash specimen than in the OPC specimen, which may have balanced out the effect of the smaller crack opening displacement.

Table 3. Solute diffusion coefficients along the crack $\left(\mathrm{m}^{2} / \mathrm{s}\right)$.

\begin{tabular}{ccc}
\hline $\begin{array}{c}\text { Time period } \\
\text { (h) }\end{array}$ & $\begin{array}{c}\text { OPC, saturated } \\
\text { (C1) }\end{array}$ & $\begin{array}{c}\text { Fly ash, saturated } \\
\text { (C2) }\end{array}$ \\
\hline $0-1$ & $4.4 \times 10^{-8}$ & $3.0 \times 10^{-8}$ \\
$1-3$ & $8.2 \times 10^{-10}$ & $8.0 \times 10^{-10}$ \\
$3-9$ & $2.5 \times 10^{-10}$ & $2.4 \times 10^{-10}$ \\
$9-24$ & $9.5 \times 10^{-11}$ & $9.3 \times 10^{-11}$ \\
\hline
\end{tabular}

\subsection{Diffusion coefficient in mortar matrix}

The solute diffusion coefficient was also calculated for diffusion into the mortar matrix from the crack wall. The method of calculation was generally the same as that for calculating the diffusion coefficient in the crack, with the difference being that the calculation was based on the entire CT value profile from the crack wall, not just the maximum value as in the case of diffusion in the crack. It was found that the diffusion coefficient perpendicular to the crack wall varied widely depending on the location of measurement in the specimen, as well as over time. This may be affected by the pore structure characteristics as well as the presence of aggregates and air voids. However, the average value for OPC $\left(6.46 \times 10^{-12} \mathrm{~m}^{2} / \mathrm{s}\right)$ was larger than that for fly ash $\left(2.88 \times 10^{-12} \mathrm{~m}^{2} / \mathrm{s}\right)$, and these fall within the ranges reported by other research (Bucur, Olteanu, Cristache, \& Pavelescu, 2010; Kumar \& Roy, 1986;).

\subsection{Discussion on the transport mechanism}

In the prismatic specimens, the effect of a dry mortar matrix versus a saturated one on the solute transport behavior was clearly seen in the X-ray CT images. In the dry specimen, transport of the cesium solution occurred mainly by absorption in the dry mortar matrix from the exposed surface on the bottom of the specimen. This process occurred very quickly compared to the transport behavior observed in the saturated specimen, and there did not appear to be any variation in the solution concentration; that is, the solution was moving as a front through the mortar matrix. The artificial crack appeared to have only a small influence on the transport behavior, as the penetration depth from the exposed surface around the tip of the crack was more than in the areas further away from the crack. This effect, however, decreased over time.

The transport behavior of the cesium solution in the saturated specimen, however, was markedly different: the solute diffusion occurred entirely along and from the artificial crack surface. Even after just $3 \mathrm{~h}$, the solute had already reached the tip of the crack, and from that point onward, the solution concentration around the crack continued to increase while diffusing gradually into the mortar matrix around the crack. It is possible that this behavior was caused by a drying of the mortar along the crack surface due to moisture evaporation, as the crack did not appear to be filled with solution, which would then lead to absorption of the solute from the bottom. The transport of the solution then proceeded as a cycle of drying, followed by absorption and diffusion along the crack surface.

In the cylindrical specimens, the effects of slightly different crack geometries and different binder types on the solute diffusion in both the crack space and perpendicular to the crack wall were examined. Diffusion of the solution within the crack occurred at different rates over time, with the initial coefficient of diffusion higher than the coefficient of diffusion in free water. This suggested that another mechanism may be at work during the early period of the solute transport, but during later periods, the transport appeared to be limited by the diffusion mechanism. 
The saturation level of the crack itself also affected the ability of the solution to fill the crack, and the presence of air voids in the partially saturated crack space suggests that some suction behavior may also have contributed to the solute transport. The crack geometries of the two specimens were somewhat similar, with the fly ash specimen having a smaller crack opening but greater constrictivity in the crack space, and the balance of these two effects may have resulted in a similar solute diffusion coefficient being observed in the crack. When examining the difference in diffusion coefficients in the mortar matrix perpendicular to the crack wall between OPC and fly ash, it was found that fly ash had a greater resistance to solution penetration. Considering that the solution concentration in the crack itself was similar, the lower diffusion coefficient in the fly ash mortar may be attributed to the denser pore structure of fly ash.

\section{CONCLUSION}

In this article, the utility of X-ray CT for understanding mass transport behavior in cracked concrete using a cesium solution as a tracer was demonstrated through the introduction and summary of two research studies. The results showed that different transport mechanisms were active depending on the saturation level of the mortar matrix, the characteristics of the crack, and the binder composition. The penetration depth of the cesium solution could be determined by examining the CT value profile and, when the results are from an in situ test, the profiles can be used to calculate the diffusion coefficient, both in the crack and in the mortar matrix. The transport progress of the solution could also be visualized in three dimensions through image analysis and reconstruction. Overall, the combination of visual and quantitative examinations of the solute diffusion behavior demonstrated how X-ray CT may be utilized for better understanding the transport mechanism in cracked concrete.

\section{ACKNOWLEDGMENTS}

This research was partially supported by the Japan Society for the Promotion of Science (Scientific Research B, project no. 23360187).

\section{REFERENCES}

Bucur, C., Olteanu, M., Cristache, C., \& Pavelescu, M. (2010). Radionuclide transport through cement matrices. Revista De Chimie, 61(5), 458-461.
Darma, I. S., Sugiyama, T., \& Promentilla, M. A. B. (2013). Application of X-ray CT to study diffusivity in cracked concrete through the observation of tracer transport. Journal of Advanced Concrete Technology, 11, 266-281.

Flury, M., \& Gimmi, T. (2002). Solute diffusion. Methods of soil analysis, part 4, physical methods Dane, J. H., \& TOPP, G. C. eds. (pp. 1323-1351). Madison, WI: Soil Science Society of America.

Henry, M., Darma, I. S., \& Sugiyama, T. (2014). Analysis of the effect of heating and re-curing on the microstructure of high-strength concrete using $\mathrm{X}$-ray CT. Construction and Building Materials. (in press).

Ikeda, S., Sugiyama, T., Kikkawa, T., \& Shimura, K. (2012). Study on transport phenomenon in crack using the cesium carbonate as a tracer by X-ray CT. Proceedings of the Concrete Structure Scenarios, JSMS, 12, 207-214. (in Japanese).

Jang, S. Y., Kim, B. S., \& Oh, B. H. (2011). Effect of crack width on chloride diffusion coefficient of concrete by steady-state migration test. Cement and Concrete Research, 41(1), 9-19.

Kikkawa, T., Sugiyama, T., Darma, I. S., \& Shimura, K. (2012). Observation of flexural cracking and cesium carbonate transport using X-ray $\mathrm{CT}$. Proceedings of the Japan Concrete Institute Annual Conference, 34(1), 1810-1815. (in Japanese).

Kumar, A., \& Roy, D. M. (1986). Retardation of $\mathrm{Cs}^{+}$and $\mathrm{Cl}^{-}$diffusion using blended cement ad mixtures. Journal of American Ceramic Society, 69(4), 356-360.

Landis, E. N., \& Keane, D. T. (2010). X-ray microtomography. Materials Characterization, 61, 1305-1316.

Li, Y. H., \& Gregory, S. (1974). Diffusion of ions in sea water and in deep-sea sediment. Geochimica et Cosmochimica Acta, 38, 703-714.

Promentilla, M. A. B., \& Sugiyama, T. (2010). X-ray microtomography of mortars exposed to freezingthawing action. Journal of Advanced Concrete Technology, 8(2), 97-111.

Sugiyama, T., Promentilla, M. A. B., Hitomi, T., \& Takeda, N. (2010). Application of synchrotron microtomography for pore structure characterization of deteriorated cementitious materials due to leaching. Cement and Concrete Research, 40(8), 1265-1270. 